\title{
Glugea jazanensis sp. nov. infecting Lutjanus bohar in the Red Sea: ultrastructure and phylogeny
}

\author{
Abdel-Azeem S. Abdel-Baki ${ }^{1,2}$, Ahmad F. Tamihi ${ }^{1}$, Hussain A. Al-Qahtani ${ }^{1}$, \\ Saleh Al-Quraishy ${ }^{1, *}$, Lamjed Mansour ${ }^{1,3}$ \\ ${ }^{1}$ Zoology Department, College of Science, King Saud University, Saudi Arabia, PO Box 2455, Riyadh 11451, Saudi Arabia \\ ${ }^{2}$ Zoology Department, Faculty of Science, Beni-Suef University, Beni-Suef, Egypt \\ ${ }^{3}$ Unité de Recherche de Biologie intégrative et Ecologie évolutive et Fonctionnelle des Milieux Aquatiques, \\ Département de Biologie, Faculté des Sciences de Tunis, Université de Tunis El Manar, Tunis, Tunisia
}

\begin{abstract}
During a survey of the microsporean fauna of the two-spot red snapper Lutjanus bohar Forsskål, 1775, from the Red Sea off Jizan (Saudi Arabia), a species of Glugea Thélohan, 1891 was found that did not conform to any known species. The species is characterized by the presence of spherical xenomas (ca. 2-5 mm in diameter) in the host body cavity. Examination of the lifecycle stages and mature spores using light and transmission electron microscopy also revealed morphological characteristics typical of species of the genus Glugea. Spores were elongated-ovoid with a posterior vacuole surrounded by the polar filament coils. Mature spores were 4.5 (4.0-4.8) $\mu \mathrm{m}$ long and $2.5(2.0-2.5) \mu \mathrm{m}$ wide. The polar filament was isofilar with 28 to 30 coils, although in most cases 29 coils, organized in 3 rows. Phylogenetic study based on the partial sequence of the small subunit (SSU) rRNA gene clustered the new microsporidia within the clade grouping species of the genus Glugea. The comprehensive analysis of the parasite's ultrastructural characteristics, together with molecular data for the SSU rDNA gene, suggests that this parasite is a new species of the genus Glugea, for which the name Glugea jazanensis sp. nov. is proposed.
\end{abstract}

KEY WORDS: Parasite $\cdot$ Microsporea $\cdot$ Glugea $\cdot$ Ultrastructure $\cdot$ SSU rDNA gene $\cdot$ Microsporidia $\cdot$ Glugeidae $\cdot$ Red snapper

\section{INTRODUCTION}

Microsporidia are obligate intracellular parasites comprising some 1500 species which parasitize a wide variety of invertebrate and vertebrate hosts (Vávra \& Lukeš 2013). These organisms have long been known to be causative agents of economically important diseases in insects (silk worms and honey bees), fish and mammals, and they also emerged as important opportunistic pathogens when AIDS became pandemic (Mathis et al. 2005). Classification of microsporidia is primarily based on structural characters observed under light and electron microscopy (Issi 1986, Sprague et al. 1992); however, small sub- unit ribosomal DNA (SSU rDNA) gene sequences are now often used as a supporting, and sometimes even the principal, tool in defining taxa (Vávra \& Lukeš 2013).

The fish family Lutjanidae contains 17 genera and 109 species, which are mainly confined to tropical and subtropical seas (Kumar et al. 2014). Lutjanus Bloch, 1790 is thus far the largest genus with 70 species, including at least 43 species from the Indo-West Pacific region (Allen et al. 2013). Of these species, the two-spot red snapper or red bass L. bohar Forsskål, 1775, is a large tropical reef fish that has a widespread distribution throughout the Indo-West Pacific, occurring from the Marquesas and Line Islands to 
East Africa, and from Australia northward to the Ryuku Islands (Marriott \& Mapstone 2006). This species is commercially important and is also prized as a game fish (Allen 1985). Despite the diversity of the family Lutjanidae, only 1 species of microsporidians has been described from this family. This species is Microfilum lutjani, which was described from L. fulgens by Faye et al. (1991). In the present study, we used morphological, ultrastructural and molecular approaches to describe Glugea jazanensis sp. nov., which was found to infect the abdominal cavity of L. bohar from the Red Sea off the coast of Saudi Arabia at Jizan.

\section{MATERIALS AND METHODS}

\section{Light and transmission electron microscopy}

From April 2013 to April 2014, 360 specimens of Lutjanus bohar (Teleostei: Lutjanidae) known by the Saudi common name 'Bohar', were collected from the Red Sea (16 53' 21' N, $42^{\circ} 32^{\prime} 3^{\prime \prime}$ E), Jizan City, Saudi Arabia. The fish were necropsied and all organs were examined for microsporean infection. Fresh spores were measured and photographed using an Olympus BX51 microscope with an Olympus DP71 camera. Measurements are based on 30 fresh spores, and data are presented as mean \pm SD (range). For ultrastructural studies, xenomas and a small part of the surrounding tissues were excised and fixed in $3 \%$ glutaraldehyde in $0.1 \mathrm{M}$ sodium cacodylate buffer ( $\mathrm{pH} 7.4$ ) for $24 \mathrm{~h}$ at $4^{\circ} \mathrm{C}$, washed in the same buffer overnight at $4^{\circ} \mathrm{C}$ and post-fixed in $2 \% \mathrm{OsO}_{4}$, buffered with the same solution for $4 \mathrm{~h}$ at the same temperature. After dehydration in an ascending ethanol series followed by 2 changes of propylene oxide ( $4 \mathrm{~h}$ in each), the samples were embedded in Epon. Semi-thin sections were cut with a Leica ultracut UC7 and stained with toluidine blue for examination by light microscopy. Meanwhile, ultra-thin sections were contrasted with uranyl acetate and lead citrate to be examined with a JEOL-JSM-1011 transmission electron microscope at $80 \mathrm{kV}$.

\section{Molecular studies}

DNA extraction was carried out from individual xenomas using the Qiagen DNeasy kit. A partial sequence of the SSU rRNA gene was amplified by PCR using the universal primers V1f 5'-CAC CAG GTT GAT TCT GCC TGA C-3' and 1942R 5'-GGT
TAC CTT GTT ACG ACT T-3'. Amplifications were performed in a final volume of $30 \mu \mathrm{l}$ of PCR mixture containing $1 \times$ Taq DNA polymerase buffer (MBI, Fermentas), $0.2 \mathrm{mmol}$ of mixed dNTP, $1.5 \mathrm{mmol}$ of $\mathrm{MgCl}_{2}, 0.2 \mathrm{pmol}$ of each primer, $1 \mathrm{U}$ of Taq DNA polymerase, 50-100 ng of DNA and ultra-pure water. The amplification was done in a thermocycler apparatus (Techne TC-Plus Satellites). The PCR program used was composed of an initial denaturation stage at $94^{\circ} \mathrm{C}$ for $4 \mathrm{~min}$, followed by 30 cycles of $94^{\circ} \mathrm{C}$ for $30 \mathrm{~s}$, $54^{\circ} \mathrm{C}$ for $30 \mathrm{~s}$ and $72^{\circ} \mathrm{C}$ for $60 \mathrm{~s}$, and a final extension stage at $72^{\circ} \mathrm{C}$ for $5 \mathrm{~min}$. Positive and negative controls were included in all PCR amplifications. Subsequently, PCR products were separated in $1 \%$ agarose gel electrophoresis in a Tris-borate-EDTA buffer (0.045 M Tris-borate, 0.001 M EDTA pH 8.0), stained with ethidium bromide and visualized on a UV transilluminator using a gel documentation sys-

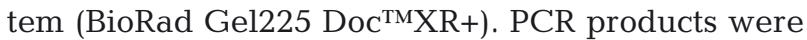
sequenced by Macrogen Inc., using the same primers employed for PCR amplification.

\section{Phylogenetic analysis}

The newly obtained SSU rDNA was aligned with several other sequences of closely related genera obtained from a BLAST query of the GenBank database (Altschul et al. 1990) using ClustalX 2.1.0.12, for which the default parameters were applied (Larkin et al. 2007). MEGA software version 5 was used to generate phylogenetic trees based on the obtained alignment by both maximum likelihood (ML) and neighbour joining (NJ) methods (Tamura et al. 2011). The parameters for the ML analyses were general time reversible model, gamma distribution with invariant sites $(\mathrm{G}+\mathrm{I})$ and 1000 bootstrap replications. The NJ tree was constructed using the Kimura 2-parameter model with a gamma distribution (Kimura 1980), for a total of 1190 positions in the final dataset. All positions containing gaps and missing data were eliminated.

\section{RESULTS}

\section{Light microscopy}

The infection was reported as dark brownish spherical xenomas in the body cavity attached to the mesenteries. These xenomas ranged from about 2 to $5 \mathrm{~mm}$. The semi-thin sections revealed that parasite xenomas were encircled by a fibrous layer produced 
by the host (Fig. 1a). If a xenoma was squeezed, numerous mature spores were released (Fig. 1b). These spores were ovoid with a posterior vacuole occupying nearly half of the spore. The fresh mature spores were $4.5 \pm$ $0.3(4.0-4.8) \mu \mathrm{m}$ long and $2.5 \pm 0.2$ (2.0-2.5) $\mu \mathrm{m}$ wide (Fig. 1b).

\section{Ultrastructure}

All lifecycle stages had isolated nuclei. Merogony was recognized as cylindrical binucleated (Fig. 1c) and multinucleated meronts with several unpaired nuclei. Meronts were surrounded by cisternae of the host cell's endoplasmic reticulum, and their cytoplasm was rich in endoplasmic reticulum (Fig. 1c). Sporonts were characterized by having a layer of amorphous materials secreted externally to their outer cell membrane, and by an increase in their cytoplasmic density (Fig. 1d). The sporonts then grouped together to form sporoblast cells (Fig. 1e). The sporoblasts gradually differentiated to the typical organelles of the spores (Figs. 1f \& 2). Mature spores were elongate-ovoid, with a double-layered wall composed of an electron-dense exospore and an electron-lucent endospore of approximately the same thickness and displaying some protu-

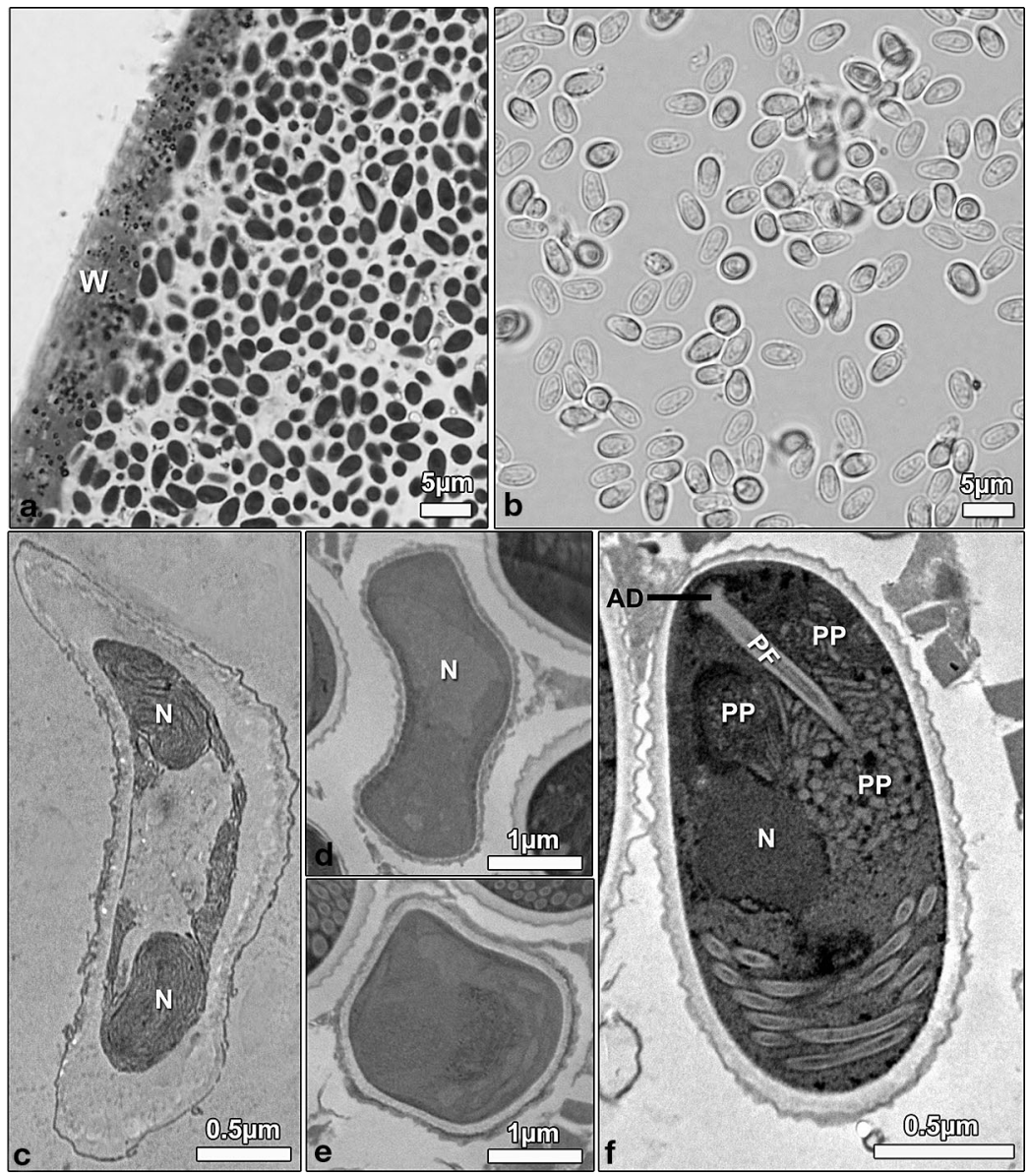

Fig. 1. Light and ultrastructural aspects of Glugea jazanensis sp. nov., a parasite in the body cavity of the two-spot red snapper Lutjanus bohar. (a) Semithin section through xemona surrounded by a wall of fibrous tissue (W) and containing aggregates of spores. (b) Fresh mature spores. (c) Meront with 2 nuclei (N). (d) Sporont with nucleus (N). (e) Sporoblast. (f) Mature spore showing anchoring disc (AD), polar filament $(\mathrm{PF})$, polaroplast $(\mathrm{PP})$ and nucleus $(\mathrm{N})$ berances (Figs. 1f \& 2a,b). The polaroplast was lamellar at the apical part and vesicular and tubular at the end of the straight part of the polar tube (Fig. 1f). The posterior vacuole was located in the third posterior part and was filled with a membranous network and fine vesicles reminiscent of the posterosome structure (Fig. 2b). The nucleus was irregular to spindle shaped and placed in the centre of the spores (Fig. 2). The anchoring disc appeared like a mushroom cap located in the centre of the anterior pole of the spore and attaching to the polar tube (Fig. 1f). The polar filament itself extended from the anchoring disc obliquely backwards and then formed the polar filament coils in the posterior half of the spore (Fig. 1f). The polar filament isofilar possessed 28 to 30 coils, but in most cases 29 coils, organized in 3 rows at the posterior pole, winding from the basal to the anterior zone of the spore (Fig. 2).

\section{Description of Glugea jazanensis sp. nov.}

\section{Systematic position}

Phylum: Microsporidia Balbiani, 1882

Class: Haplophasea Sprague, Becnel \& Hazard, 1992

Order: Glugeida Issi, 1986

Family: Glugeidae Thélohan, 1892

Genus: Glugea Thélohan, 1891

Species: Glugea jazanensis sp. nov.

Type host: Lutjanus bohar Forsskål 1775

Locality: Red Sea off Jizan City $\left(16^{\circ} 53^{\prime} 21^{\prime \prime}\right.$ N, $42^{\circ} 32^{\prime} 3^{\prime \prime}$ E), Saudi Arabia

Site of infection: Skeletal muscles of the abdominal cavity and mesenteric tissues

Prevalence of infection: $14.7 \%(53 / 360)$ 


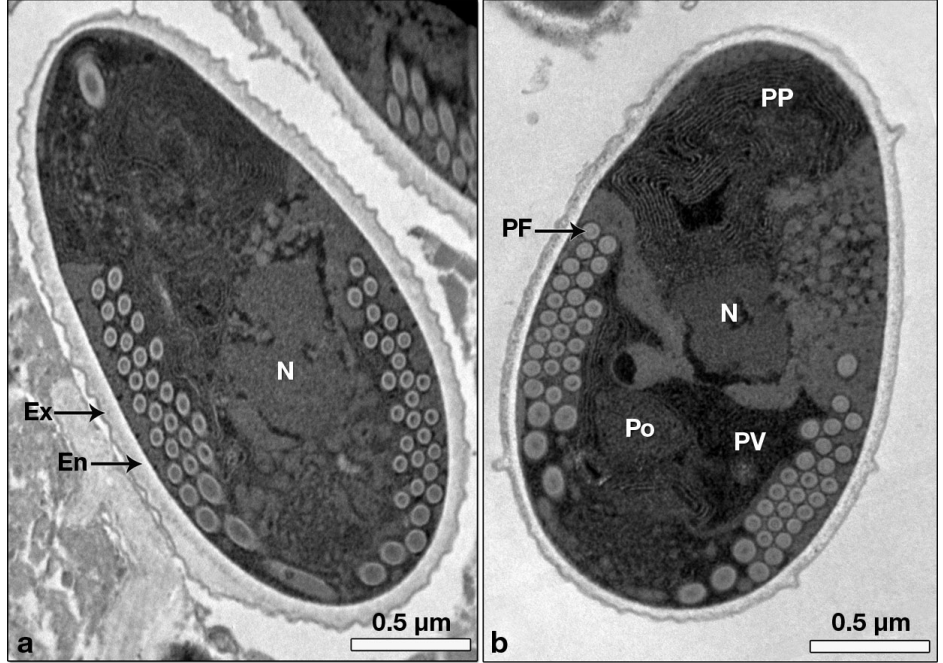

Fig. 2. Details of the ultrastructural morphology of Glugea jazanensis sp. nov. spores from the body cavity of the two-spot red snapper Lutjanus bohar. (a) Spore ultrastructure showing the spore wall, which is composed of the exospore (Ex) and endospore (En). N: nucleus. Polar filament $(\mathrm{PF})$, polaroplast $(\mathrm{PP})$, nucleus $(\mathrm{N})$ and posterior vacuole $(\mathrm{PV})$ with posterosome $(\mathrm{Po})$

Type specimen: Two slides containing semi-thin sections of xenomas containing spores at different developmental stages of the hapantotype were deposited in the parasitological collection of the Hungarian Natural History Museum under the inventory number HNHM- 70640.

Etymology: The specific epithet 'jazanensis' derives from the host locality Jizan City.

\section{Molecular analysis}

An SSU rDNA sequence of 1234 bp was generated for the new microsporidian and deposited in GenBank under accession number KP262018. Multiple sequence alignment showed strong similarity with microsporidia belonging to the genus Glugea (Table 1). The highest percentages of similarities were 99.62 and $99.56 \%$ observed, respectively, with G. nagelia Abdel-Baki, Al-Quraishy, Rocha, Dkhil, Casal \& Azevedo, 2015, from Cephalopholis hemistiktos (Actinopterygii: Serranidae) off the Red Sea and Glugea sp. Wu, Wu, Wu \& Wang, 2002 from Epinephelus awoara. Similarity with other Glugea species varied between 91.95 and $90.3 \%$ (Table 1). Species of the genus Pleistophora had similarities varying between 87.6 and $85.4 \%$. ML and NJ yielded trees with similar topology. The present species forms a highly supported subclade (bootstrap $=100 \%$ ) with G. nagelia and the unidentified Glugea species hav-

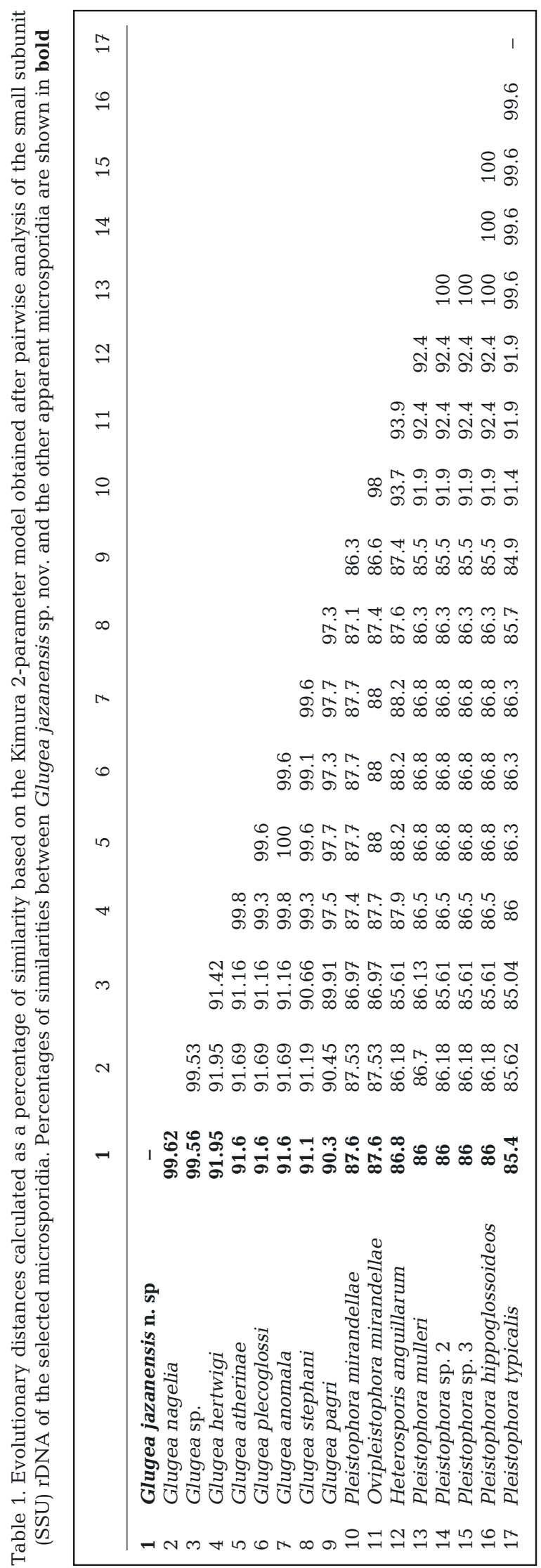


ing a GenBank entry AY090038 (direct submission by Wu et al. in 2002) from E. awoara within the large clade grouping all selected Glugea species (Fig. 3).

\section{DISCUSSION}

According to available literature, 17 species of the genus Glugea have so far been described from fresh and marine fish (Su et al. 2014), although some of these species might be synonymous, since their classification is based mainly on spore morphology and host origin (see Vagelli et al. 2005). Of all currently described species of the genus Glugea, 7 species have been reported from freshwater hosts, and these can be regarded as separate species which do not need to be compared with the present species. Of the remaining species, G. berglax Lom \& Laird, 1976; G. plecoglossi Takahashi \& Egus, 1977; and G. athe-

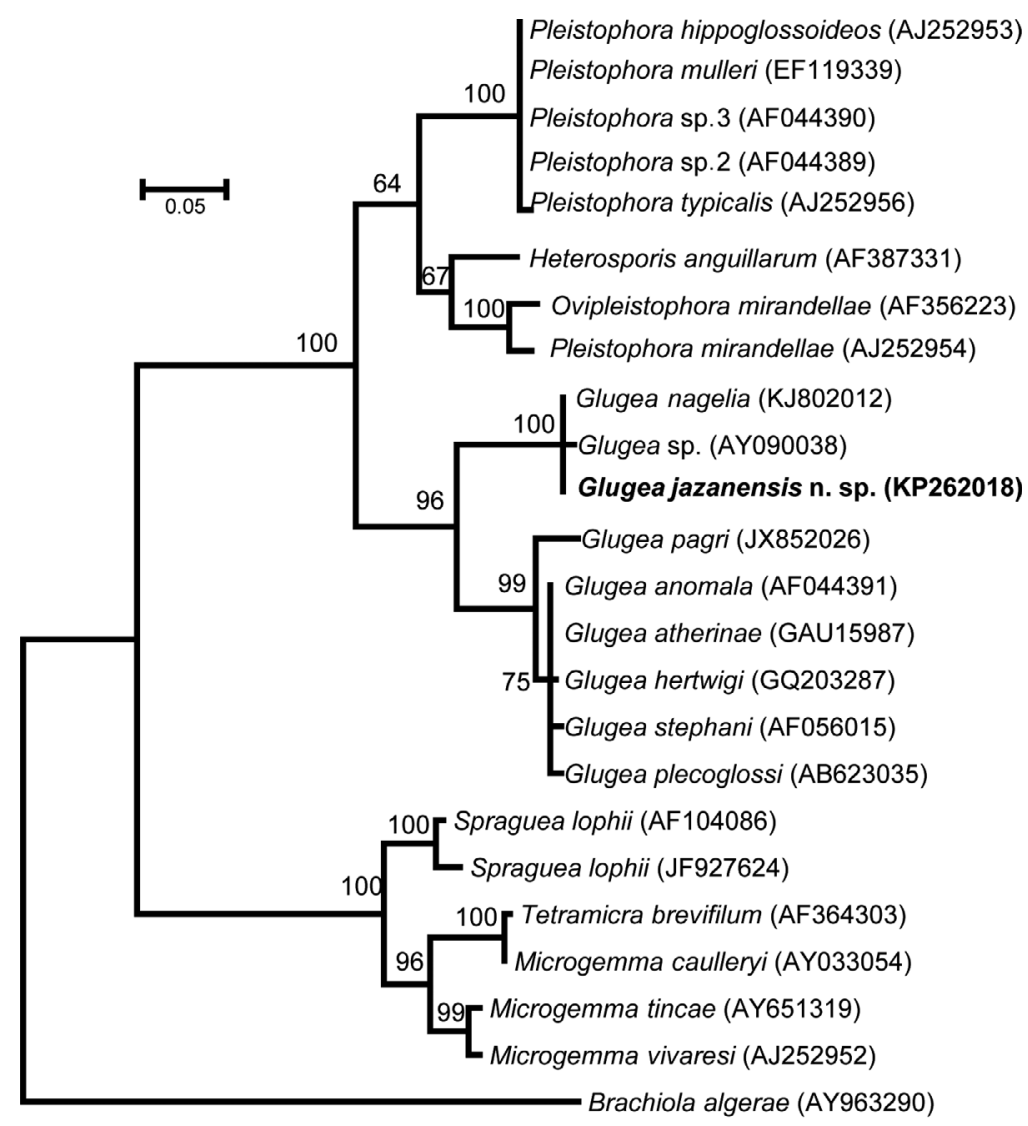

Fig. 3. Maximum likelihood (ML) phylogenetic tree based on the small subunit (SSU) rDNA data set of selected microsporidian species showing the position of Glugea jazanensis sp. n. Bootstrap values from ML analysis are indicated at each node. GenBank accession numbers for each species are reported in parentheses. Bootstrap supports based on 1000 replicates are given in branches. Brachiola algerae was used as the outgroup. Scale bar shows the number of changes per site rinae Berrebi 1979 differ in having longer spores (6.4, 5.8 and $5.7 \mu \mathrm{m}$, respectively, vs. $4.5 \mu \mathrm{m}$; see Lom \& Dyková 1992). Although a notable feature of the members of the genus Glugea is the presence of a single mature spore type, as in the present species, the existence of Glugea species with 2 types of spores has been reported previously (e.g. G. vincentiae, Vagelli et al. 2005; and G. pagri, Su et al. 2014). The number of polar filament coils in mature spores is also a common diagnostic for microsporidian species (Lovy et al. 2009). Our present species showed 29 to 34 polar filament coils in 3 rows inside the spore, which greatly exceeds the range of coils in any previously described Glugea spp. (see Su et al. 2014). The previously described microsporidian from fish of the family Lutjanidae was Microfilum lutjani, which was found in the gill filaments of Lutjanus fulgens (Faye et al. 1991). This species differs from our present species in having a very characteristic uncoiled polar filament that has not been described previously in the Microsporidia. It is worth mentioning that the present new species is similar to G. nagelia (the only species described for this genus in Saudi Arabia; see Abdel-Baki et al. 2015) in terms of host habitat and spore shape, although it differs in terms of site of infection (body cavity vs. intestinal wall), spore size $(4.5 \times$ $2.5 \mu \mathrm{m}$ vs. $5.1 \times 2.2 \mu \mathrm{m}$ ) and the number of the filament coils (28-30 vs. 26-29).

Overall, therefore, based on these morphometric comparisons, the present species can be considered a new species. Although careful morphological study continues to be indispensable for proper identification and subsequent reorganization of existing and new species (Lom \& Nilsen 2003), this should be supported by the comparison of SSU rDNA sequences, especially when describing a new species (Vávra \& Lukeš 2013). Molecular analyses based on the SSU rDNA gene, either using the evolutionary genetic distance or the phylogenetic analyses, are especially informative. In this study, the new species was shown to possess the highest percentages of similarity with other species of the genus Glugea. The highest percentages of similarity were observed with G. nagelia (99.62\%) and with the unidentified Glugea species (99.56\%). The phylogenetic tree shows clustering of the 3 species in the same subclade with a boot- 
strap value of $100 \%$. The second subclade in the clade of Glugea is formed by G. anomala (PomportCastillon et al. 2000), G. atherinae, G. hertwigi (Lovy et al. 2009), G. stephani (Pomport-Castillon et al. 2000) and G. plecoglossi (Pomport-Castillon et al. 2000). It is worth noting that the percentages of similarities between these 5 species vary between $97.7 \%$ (G. pagri vs. G. anomala) and 99.8\% (G. anomala vs. $G$. hertwigi), while $G$. anomala and $G$. atherinae appear identical with $100 \%$ similarity. A high percentage of similarity was also observed within thegenus Pleistophora; for example, P. aegyptiaca showed $99.8 \%$ similarity with $P$. anguillarum (AbdelGhaffar et al. 2012). Thus, considering the evolutionary genetic distances and the phylogenetic analysis, we believe that the present SSU rDNA study, along with the structural and ultrastructural data, supports the establishment of $G$. jazanensis as a new species distinct from any other sequenced Glugea species.

Acknowledgements. We extend our appreciation to the Dean of Scientific Research, King Saud University, for funding the work through the research group project number PRG-1436-02.

\section{LITERATURE CITED}

Abdel-Baki AA, Al-Quraishy S, Rocha S, Dkhil MA, Casal G, Azevedo C (2015) Ultrastructure and phylogeny of Glugea nagelia sp. n. (Microsporidia: Glugeidae), infecting the intestinal wall of the yellowfin hind, Cephalopholis hemistiktos (Actinopterygii: Serranidae), from the Red Sea. Folia Parasitol 62:1-7

Abdel-Ghaffar F, Bashtar AR, Morsy K, Mehlhorn H, Al Quraishy S, Al-Rasheid K, Abdel-Gaber R (2012) Morphological and molecular biological characterization of Pleistophora aegyptiaca sp. nov. infecting the Red Sea fish Saurida tumbil. Parasitol Res 110:741-752

Allen GR (1985) FAO species catalogue, Vol 6. Snappers of the world. An annotated and illustrated catalogue of lutjanid species known to date. FAO, Rome

Allen GR, White WT, Erdmann MV (2013) Two new species of snappers (Pisces: Lutjanidae: Lutjanus) from the IndoWest Pacific. J Ocean Sci Found 6:33-51

Altschul SF, Gish W, Miller W, Myers EW, Lipman DJ (1990) Basic local alignment search tool. J Mol Biol 215:403-410 - Faye N, Toguebaye BS, Bouix G (1991) Microfilum lutjani n.

Editorial responsibility: Dieter Steinhagen, Hannover, Germany g. n. sp. (Protozoa Microsporida), a gill parasite of the golden African snapper Lutjanus fulgens (Valenciennes, 1830) (Teleost Lutjanidae): developmental cycle and ultrastructure. J Protozool 38:30-40

Issi IV (1986) Microsporidia as a phylum of parasitic protozoa. Protozoologiya 10:6-136

Kimura M (1980) A simple method for estimating evolutionary rates of base substitutions through comparative studies of nucleotide sequences. J Mol Evol 16:111-120

Kumar SD, Nair RJ, Kuriakose S (2014) Midnight snapper Macolor macularis (Perciformes: Lutjanidae) - a new record of snapper from Indian waters. Mar Biodivers Rec $7: 1-4$

Larkin MA, Blackshields G, Brown NP, Chenna R and others (2007) Clustal W and Clustal X version 2.0. Bioinformatics 23:2947-2948

Lom J, Dyková I (1992) Protozoan parasites of fishes. Elsevier Science Publishers, Amsterdam

Lom J, Nilsen F (2003) Fish microsporidia: fine structural diversity and phylogeny. Int J Parasitol 33:107-127

Lovy J, Kostka M, Dyková I, Arsenault G, Pecková H, Wright GM, Speare DJ (2009) Phylogeny and morphology of Glugea hertwigi from rainbow smelt Osmerus mordax found in Prince Edward Island, Canada. Dis Aquat Org 86:235-243

Marriott RJ, Mapstone BD (2006) Consequences of inappropriate criteria for accepting age estimates from otoliths, with a case study for a long-lived tropical reef fish. Can J Fish Aquat Sci 63:2259-2274

> Mathis A, Weber R, Deplazes P (2005) Zoonotic potential of the microsporidia. Clin Microbiol Rev 18:423-445

> Pomport-Castillon C, De Jonckheere JF, Romestand B (2000) Ribosomal DNA sequences of Glugea anomala, G. stephani, G. americanus and Spraguea lophii (Microsporidia): phylogenetic reconstruction. Dis Aquat Org 40: 125-129

Sprague V, Becnel JJ, Hazard EI (1992) Taxonomy of the phylum Microspora. Crit Rev Microbiol 18:285-395

Su Y, Feng J, Sun X, Jiang J, Guo Z, Ye L, Xu L (2014) A new species of Glugea Thélohan, 1891 in the red sea bream Pagrus major (Temminck \& Schlegel) (Teleostei: Sparidae) from China. Syst Parasitol 89:175-183

> Tamura K, Peterson D, Peterson N, Stecher G, Nei M, Kumar S (2011) MEGA5: molecular evolutionary genetics analysis using maximum likelihood, evolutionary distance, and maximum parsimony methods. Mol Biol Evol 28: 2731-2739

> Vagelli A, Paramá A, Sanmartín ML, Leiro J (2005) Glugea vincentiae n. sp. (Microsporidia: Glugeidae) infecting the Australian marine fish Vincentia conspersa (Teleostei: Apogonidae). J Parasitol 91:152-157

Vávra J, Lukeš J (2013) Microsporodia and 'the art of living together'. Adv Parasitol 82:253-319

Submitted: March 5, 2015; Accepted: September 14, 2015 Proofs received from author(s): October 15, 2015 